\title{
On the Auditory Transmission using Brainstem Evoked Response Audiometry in Indian Women with Iron Deficiency Anemia
}

\author{
Umme Kulsoom Sheema and Alka Rawekar \\ Department of Physiology, Jawaharlal Nehru Medical College (JNMC), DMIMS (Deemed University), \\ Sawangi (M), Wardha (Maharashtra)Email: ummekulsoom22@gmail.com
}

\section{ABSTRACT}

Iron deficiency anemia is a common nutritional disorder prevalent in many developing and underdeveloped countries. It affects various physiological aspects that have been vastly explored by researchers during developmental and nondevelopmental phases. The anemic status due to iron deficiency possibly leads to various neurodeficits and functional impairment. Brainstem evoked response audiometry (BERA) is an objective electrophysiological method used for assessing the transmission in the auditory pathways from the auditory nerve to the brainstem. Since iron deficiency anemia is widespread in women belonging to reproductive age, the present study aims to explore the impact of this type of anemia on hearing. The study included 30 anemic adult females belonging to the age group 18-30 years and 30 age matched controls. Hemoglobin and serum ferritin levels were investigated to evaluate the anemic status. BERA was performed on them to assess the auditory transmission. Results were compared between two groups by unpaired Student's t-test. A p value $<0.05$ was considered significant. Mild increase in absolute latencies of wave I, III, V and mild increase inter-peak latencies of waves I - III, III - V and I-V in anemic group when compared to healthy controls, which was not statistically significant. Iron deficiency anemia may possibly effect the impulse transmission in auditory pathway, which may lead to sensorineural hearing loss in women.

KEY WORDS: ANAEMIA, NUTRITIONAL ANEMIA, ADULT FEMALES, EVOKED POTENTIALS, DEAFNESS.

\section{INTRODUCTION}

Anemia is a major health problem present globally affecting 1.6 billion people which is estimated to be $24.8 \%$ of the population, of which iron deficiency is a major contributing factor. The WHO estimates that Iron Deficiency Anemia (IDA) affects 30\% of non-pregnant women of reproductive age and 42\% of pregnant women. Women in developing countries are more susceptible to this deficiency due to low dietary intake, menstrual blood loss, and increased demand during pregnancy and lactation. National Family Health Survey (NFHS)-4 done in India during the year 2015-16 shows a prevalence of IDA in 53\% of women belonging to the age group of 15-49 years (Alecia 2014).

Biosc Biotech Res Comm P-ISSN: 0974-6455 E-ISSN: 2321-4007
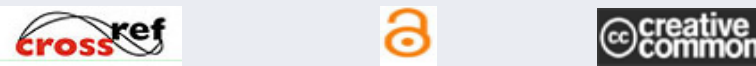

Identifiers and Pagination

Article Information

Year: 2021 Vol: 14 No (9) Special Issue

Pages: 223-226

Received: $13^{\text {th }}$ Apr 2021

This is an open access article under Creative

Commons License Attribn 4.0 Intl (CC-BY).

DOI: $h t t p: / / d x . d o i . o r g / 10.21786 / b b r c / 14.9 .42$
According to WHO, IDA in non-pregnant adult females is blood hemoglobin $<12 \mathrm{~g} / \mathrm{dl}$ and serum ferritin $<15 \mathrm{ng} / \mathrm{ml}$. Iron is not only required during early developmental stages for normal brain growth but also plays an important role in later part of life for the maintenance of various metabolic activities and physiological functions. Besides iron having a key role in hemoglobin synthesis, it is required for non-hematological functions by nervous system during development (in-utero, infancy and childhood). Myelin synthesis, development of oligodendrocytes, neurogenesis, synthesis of neurotransmitters like dopamine, serotonin, catecholamines and GABA, all are iron dependent.

Researchers have found that iron is required during nondevelopmental phases of life as well. The uptake of iron by the brain lasts throughout the life and is utilized by the oligodendrocytes for formation and maintenance of myelin . Since myelin is involved in conduction in the nerve fibres, iron deficiency anemia which is a severe form of iron deficiency may be associated with alteration in brainstem auditory evoked potentials. BERA is used to assess the auditory transmission i.e generation and conduction of impulse in the auditory pathway. BERA represents the progressive activation of different levels of the auditory pathway consisting of I - V waves.

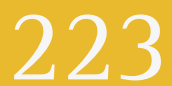


Waves I \& II arises from cochlear nerve, wave III from Cochlear Nucleus, wave IV from Superior Olivary Nucleus and wave V from Lateral Lemniscus. Latency of Wave I indicates peripheral transmission and wave III and $\mathrm{V}$ indicates brainstem transmission of auditory impulses. The inter peak latency between wave I-V depicts conduction time and is an index of central nervous system development. BERA can be used extensively to identify subclinical lesions associated with various demyelinating diseases and post hypoxic damage .Hence, we undertook the present study to explore whether iron deficiency anemia effects the brainstem auditory evoked potential and in turn on hearing in adult life.

\section{MATERIAL AND METHODS}

The study was conducted in the Central Neuro-Physiology lab of Acharya Vinoba Bhave Rural hospital and teaching institute, Jawaharlal Nehru Medical College, Wardha. The cases (30) included females in the age group of 18 -30 years whose blood hemoglobin level $<12 \mathrm{~g} / \mathrm{dl}$ and serum ferritin < $15 \mu \mathrm{g} / \mathrm{L}$. The comparison group (30) (Normal females without IDA- non anemic) were age matched females with normal blood hemoglobin and Serum Ferritin levels.i.e hemoglobin levels $>12 \mathrm{~g} / \mathrm{dl}$ and Serum ferritin levels $>15 \mu \mathrm{g} / \mathrm{L}$ (Algarin 2003).

The following was the exclusion criteria- Current pregnancy or pregnancy within the previous year, current lactation, hormonal contraceptive use, irregular menses, current blood donation, pre-existing ear diseases with clinical deafness, endocrine disorders (e.g: Diabetes Mellitus, Thyroid dysfunction), Neurological diseases and other types of anemia (Biacabe et al., 2001).

Table 1. Age \&t hematological parameters of anemic \&t non-anemic females.

\begin{tabular}{|l|c|c|}
\hline Study Parameters & $\begin{array}{c}\text { Cases }(30 \mathrm{~N}) \\
\text { mean } \pm \text { SD }\end{array}$ & $\begin{array}{c}\text { Controls }(30 \mathrm{~N}) \\
\text { mean }_{ \pm} \text {SD }\end{array}$ \\
\hline Age (years) & $25.24 \pm 1.6$ & $25.07 \pm 1.2$ \\
\hline Hemoglobin $(\mathrm{gm} / \mathrm{dl})$ & $10.90 \pm 2.14$ & $12.56 \pm 0.80$ \\
\hline Serum ferritin $(\mu \mathrm{g} / \mathrm{L})$ & $12.75 \pm 0.62$ & $24.27 \pm 1.12$ \\
\hline
\end{tabular}

Table 2. Absolute latencies of waves I, III \& $\mathrm{V}$ of anemic at non-anemic females.

\begin{tabular}{|l|c|c|}
\hline $\begin{array}{l}\text { Absolute Latencies } \\
(\mathrm{ms})\end{array}$ & $\begin{array}{c}\text { Cases } \\
\text { mean } \pm \text { SD }\end{array}$ & $\begin{array}{c}\text { Controls } \\
\text { mean } \pm \text { SD }\end{array}$ \\
\hline Wave I & $1.84 \pm 0.23$ & $1.62 \pm 0.31$ \\
\hline Wave III & $3.74 \pm 0.26$ & $3.46 \pm 0.24$ \\
\hline Wave V & $5.70 \pm .56$ & $5.53 \pm 0.30$ \\
\hline & $* p<0.05$ \\
\hline
\end{tabular}

After undergoing complete medical history and clinical examination, the suitable cases and controls were subjected to hematological evaluation and BERA recording. Blood Hemoglobin concentration was estimated using automatic Coulter method and Serum Ferritin estimation was done by ELISA (VITROS 5600 (ICSH)). BERA was recorded using Neuron Spectrum-5, Neurosoft Chroma (Russia). BERA is an evoked potential generated by a brief click transmitted from an acoustic transducer in the form of an insert earphone or headphone. The elicited waveform response is measured by surface electrodes typically placed at the vertex of the scalp and mastoid. The waveform peaks are labeled I-V. These waveforms normally occur within a 10millisecond time period after a click stimulus presented at high intensities (70 dB normal hearing level [nHL]). The following parameters were recorded - absolute latencies of wave I, II, III, IV and V with inter-peak latencies of I-III and III-V, I-V (Beard et al., 1993).

Statistical Analysis: Significance of difference in the mean values of different parameters in two groups was assessed by Student's " $t$ " test and $p$-value $<0.05$ was considered to be significant. All the values were expressed as mean and 1 standard deviation. Calculations were done using SPSS (version 18) and Microsoft Excel software (Chung et al., 2014).

\section{RESULTS AND DISCUSSION}

Total 60 subjects were included in this study, among which, 30 were anemic cases and 30 were non-anemic controls. Values of all the study parameters of the anemic cases and non - anemic controls are given in the Table 1 (Falkingham et al., 2010).

Table 3. Inter-peak latencies of anemic \&t non-anemic females.

\begin{tabular}{|l|c|c|}
\hline $\begin{array}{l}\text { Inter-peak latencies } \\
(\mathrm{ms})\end{array}$ & $\begin{array}{c}\text { Cases } \\
\text { mean } \pm \text { SD }\end{array}$ & $\begin{array}{c}\text { Controls } \\
\text { mean } \pm S D\end{array}$ \\
\hline I-III & $2.38 \pm 0.23$ & $2.12 \pm 2.43$ \\
\hline III-V & $2.40 \pm 0.49$ & $2.32 \pm 0.31$ \\
\hline I-V & $3.56 \pm 0.48$ & $3.11 \pm 0.12$ \\
\hline${ }^{*} p<0.05$ & & \\
\hline
\end{tabular}

The absolute latencies (Table 2) and inter-peak latencies (Table 3) of the anemic females were prolonged when compared to non-anemic females but were not statistically significant ( $p>0.05)$ (Ferraro \&t Durrant 1994).

Anemia, particularly iron deficiency anemia is a prevalent disorder either due reduced intake or increased loss. 53\% of Indian women belonging to reproductive age group suffer from Iron deficiency anemia. The major cause of anemia in women is due to nutritional deficiency, increased requirement during pregnancy 
and lactation, loss during menstruation and parturition, intake of phytates. Iron deficiency anemia is a grave form of iron deficiency and this deficiency has an impact on various physiological functions. BERA is a noninvasive electrophysiological tool to assess the auditory transmission. The different structures of the auditory pathway are stimulated and recorded from the scalp and mastoid using electrodes. The wave I is generated from cochlea, wave III is generated from cochlear nucleus and wave $\mathrm{V}$ is generated from lateral lemniscus and inferior colliculus (Hill 1989) (Lozano et al., 2019; Lozoff 2007; McLean et al., 2019; Shankar et al., 2000; Ortiz et al., 2004; Ramit \&t Das 2016).

Alteration in the process of impulse transmission leads to prolonging of absolute latencies $(\mathrm{I}, \mathrm{III}, \mathrm{V})$ and interpeak latencies (I-III, III-V, I-V), found in disorders like demyelination, ischemia \&t degeneration leading to hearing impairment. In our study the absolute and interpeak latencies were prolonged in anemic women when compared to non-anemic women, however the difference was not statistically significant. Similar evidences were demonstrated N. Shankar et al. where the absolute \& inter-peak latencies were increased in anemic children. Ramit Dey studied 40 subjects with IDA in the age group of 12-16 years and found increased absolute latencies in the waves I, III \& $\mathrm{V}$ and also increased inter-peak latencies indicating delayed transmission in auditory pathway when compared to non-anemic subjects (Schieffer et al., 2017; Starr 1994; Stockard et al., 1993).

Algerin C et al. reported significantly prolonged absolute and inter-peak latencies in children. In a cohort study done in children the prevalence of hearing loss was $3.0 \%$ in children with IDA and $1.7 \%$ in those without IDA. Similar studies in the U.S.A and Taiwan in adult population has suggested IDA may be a significant causal factor for sensorineural hearing loss. The possible mechanisms explained for neuro-deficits in IDA are that since iron is an important cofactor required for DNA synthesis and neurotransmitter metabolism, its low levels may hamper normal physiological functioning; dependence of oligodendrocytes on iron for myelination hampers impulse transmission and low hemoglobin in anemia leads to reduced oxygen delivery leading to increased ischemia in these tissues (Wang et al., 2020).

Since there is data mounting regarding the effects of IDA during developmental stages like infancy, childhood and adolescence; the present study focuses on nondevelopmental effects of IDA in adult females. Because of high prevalence of IDA in developing countries these females are vulnerable to deleterious effects of IDA particularly auditory response. Further research studies involving larger population, correlating the different waves of BERA with different grades of anemia and prospective studies to demonstrate the effect of iron supplementation on BERA are required for confirmatory conclusions.

\section{CONCLUSION}

The findings in our are indicative of a neurological impairment consequent to IDA though, perhaps, the significance could not be revealed as women showed only mild anemia and may be greater numbers need to be studied. Correction of anemia is extremely important as persistence of anemia may lead to sensorineural hearing loss in women.

\section{REFERENCES}

Alecia J. Leonard. (2014). A Study of the Effects of Latent Iron Deficiency on Measures of Cognition: A Pilot Randomised Controlled Trial of Iron Supplementation in Young Women. Nutrients, 6, 2419-2435

Algarin C, Peirano P, Garrido M, Pizarro F, Lozoff B. (2003). Iron Deficiency Anaemia in infancy: Long lasting effects on Auditory and Visual System Functioning. Pediatric Research; 53: 217-223.

Beard JL, Connor JD, Jones BC. (1993). Brain iron: Location and function. Prog Food Nutr Sci; 17: 183221.

Biacabe B, Chevallier JM, Avan P, Bonfils P. (2001). Functional anatomy of auditory brainstem nuclei: application to the anatomical basis of brainstem auditory evoked potentials. AurisNasus Larynx; 28(1): 85-94

Chung SD, Chen PY, Lin HC, Hung SH. (2014). Sudden sensorineural hearing loss associated with iron-deficiency anemia: a population-based study. JAMAOtolaryngol;140(5):417- 22.

Falkingham et al. (2010). The effects of oral iron supplementation on cognition in older children and adults:a systematic review and meta-analysis. Nutrition Journal 9:4.

Ferraro JA, Durrant JD. (1994). Auditory evoked potentials: overview and basic principals. In: Katz J. Handbook of clinical Audiology. 4th edition. p. 31738.

Hill JM. (1989). Comments on distribution of irori in the brain. Am J Clin Nutr; 50: 616-617.

Lozano R, Fullman N, Mumford JE, Knight M, Barthelemy CM, Abbafati C, et al. (2019). Measuring universal health coverage based on an index of effective coverage of health services in 204 countries and territories, 1990-2019: a systematic analysis for the Global Burden of Disease Study. Lancet 2020

Lozoff B. (2007). Iron deficiency and child development. Food Nutr Bull 28:S560-71.

McLean E, Cogswell M, Egli I, Wojdyla D, de Benoist B. (2009). Worldwide prevalence of anaemia, WHO Vitamin and mineral nutrition information system, 1993-2005. Public Health Nutr;12:444-54

N. Shankar et al. (2000). Brainstem Auditory Evoked Potential Responses In Iron-Deficient Anemic Children. Indian J PhysiolPharmacol; 44 (3) : 297-303

National Family Health Survey (NFHS)-4 (2015-16), National and State Fact Sheets, rchiips.org.

Ortiz E, Pasquini JM, Thompson K, Felt B, Butkus G, 
Beard J, et al. (2004). Effect of manipulation of iron storage, transport, or availability on myelin composition and brain iron content in three different animal models. J Neurosci Res ;77:681-9.

Ramit Dey, Piyali Das (2016). Effect of hypochromic microcytic anemia on hearing in the adolescent age group in India, as assessed by Brainstem Evoked Response Audiometry. International Journal of Biomedical Research; 7(7): 520-523.

Schieffer KM, Chuang CH, Connor J, Pawelczyk JA, Sekhar DL. (2017). Association of iron deficiency anemia with hearing loss in US adults. JAMA Otolaryngol ;143(4):350-4.

Schieffer KM, Connor JR, Pawelczyk JA, Sekhar DL. (2017). The relationship between iron deficiency anemia and sensorineural hearing loss in the pediatric and adolescent population. Am J Audiol.;26(2):155-62.

Starr A, Nuwer MR, Aminoff M, Goodin D, Matsuoka
S. (1994) IFCN recommended standards for brainstem auditory evoked potentials. Report of an IFC committee. Electroencephalography and Clinical Neurophysiology; 91:12-17

Stockard JJ, Pope-Stockard JE, Sharbrough FW. (1993). Brainstem auditory evoked potentials in neurology: Methodology, interpretation, and clinical application. In: Aminoff MJ eds: Electro diagnosis in clinical neurology 3rd ed. New York, Churchill Livingstone; 503-536.

Wang, Haidong, Kaja M Abbas, Mitra Abbasifard, Mohsen Abbasi-Kangevari, Hedayat Abbastabar, Foad Abd-Allah, Ahmed Abdelalim, et al. (2020). "Global Age-Sex-Specific Fertility, Mortality, Healthy Life Expectancy (HALE), and Population Estimates in 204 Countries and Territories, 1950-2019: A Comprehensive Demographic Analysis for the Global Burden of Disease Study 2019." The Lancet 396, no. 10258: 1160-1203. https://doi.org/10.1016/S0140-6736(20)30977-6. 